INTERMATIONAL JOURNAL
OFARMACEUTICAL SCIENCES
PESEARCH
RESEM

Received on 31 January, 2013; received in revised form, 22 February, 2014; accepted, 03 May, 2014; published 01 June, 2014

\title{
DEVELOPMENT AND VALIDATION OF STABILITY INDICATING METHOD FOR SIMULTANEOUS ESTIMATION OF CEFTRIAXONE AND TAZOBACTAM INJECTION USING RP-UPLC METHOD
}

Vipul J. Panchal*, Hemant T. Desai and Ashwin G. Dave

Nirlife Healthcare (Healthcare Division of Nirma Limited), Sachana, Ahmedabad- 382 150, Gujarat, India

Keywords:

Ceftriaxone, Tazobactam, Method validation, RP-UPLC, Forced degradation

Correspondence to Author:

Vipul Jayantilal Panchal

Senior Quality Assurance Officer, B203, Ashirwad Residency, Nr.

Navyug School, Opp. Shivdarshan

Society, Naroda, Gujarat, India

E-mail: vipulj.2012@rediffmail.com
ABSTRACT: This research manuscript describes simple, sensitive, accurate, precise and repeatable RP- UPLC method for the simultaneous determination of Ceftriaxone (CEF) and Tazobactam (TAZ) Injection in combine dosage form. The sample was analyzed by reverse phase $\mathrm{C} 18$ column (Acquity UPLC BEH $100 \times 2.1 \mathrm{~mm}$ ID, $1.7 \mu \mathrm{m}$ ) with mobile phase. In mobile phase, Solution A containing Potassium Dihydrogen Phosphate buffer ( $\mathrm{pH}$ adjusted to $6.5 \pm 0.2$ with Orthophosphoric acid), Citric acid buffer ( $\mathrm{pH}$ adjusted to 5.0 \pm 0.2 with $\mathrm{NaOH}$ solution) and Acetonitrile and Solution B containing Tetradecyl ammonium bromide, Tetraheptyl ammonium bromide and Acetonitrile in the flow rate of $0.3 \mathrm{ml} / \mathrm{min}$. Quantification was achieved $230 \mathrm{~nm}$ with PDA detector. The retention time for Ceftriaxone and Tazobactam was found to be 2.83 and 1.72 minute respectively. The linearity for Ceftriaxone and Tazobactam was obtained in the concentration range of $40-280 \mu \mathrm{g} / \mathrm{ml}$ and 5-35 $\mu \mathrm{g} / \mathrm{ml}$ respectively. Ceftriaxone and Tazobactam API and market formulation were subjected to acid and alkali hydrolysis, oxidation, thermal and photolytic forced degradation. The peak purity of drug substance and drug product peak also confirmed the specificity of the methods with respect to the degradation products. In the forced degradation study Ceftriaxone and Tazobactam showed maximum degradation in base hydrolysis stress study followed by less degradation in thermal degradation. The developed method was simple, specific, sensitive, rapid, and economic and can be used for estimation of Ceftriaxone and Tazobactam in bulk and their combined dosage form for routine analysis and stability studies.
INTRODUCTION: Ceftriaxone Sodium (Fig. 1) is chemically known as 5-Thia-1azabicyclo[4.2.0]oct-2-ene-2-carboxylicacid,7-[[2amino-4-thiazolyl) (methoxyimino)acetyl]amino]8-oxo-3[[(1,2,5,6-tetrahydro-2-methyl-5-,6-diaxo1,2,4-triazin-3-yl)thio]methyl]-, disodium salt, [6R-[6 $\alpha, 7 \beta(\mathrm{Z})]]-$, hydrate, $2: 7$.

\begin{tabular}{|l|c|}
\hline QUICK RESPONSE CODE & DOI: \\
\hline
\end{tabular}

It is an antibacterial (Parenteral third generation cephalosporin antibiotic) inhibits bacterial cell wall synthesis of actively dividing cells by binding to one or more penicillin-binding proteins (PBPs). Tazobactum Sodium (Fig. 2) is chemically known as (2S,3S,5R)-3-methyl-7-oxo-3- (1H-1,2,3-triazol1-ylmethyl)-4-thia-1-azabicyclo [3.2.0] heptanes-2carboxylic acid 4,4-dioxide, Sodium salt. It is a penicillinate sulfone, structurally related to sulbactam. Being a betalactamase inhibitor, it is synergistic with many beta-lactamase labile drugs such as penicillins and cephalosporins. Ceftriaxone Sodium is listed in Indian Pharmacopoeia ${ }^{1}$, British Pharmacopoeia $^{2}$ and United State Pharmacopoeia ${ }^{3}$. 
Tazobactam Sodium is not official in any pharmacopoeia. Literatures survey reveals Spectroscopic ${ }^{4}$; ion-pair HPLC ${ }^{5}$, and RP-HPLC ${ }^{6}$, 7,8 methods have been reported as a single as well as combination with other drugs. However, there is no work was reported for the simultaneous estimation of these drugs by RP-UPLC method. Hence, in the present study an attempt has been made to develop simple, and accurate, sensitive, precise and repeatable RP-UPLC method, for the simultaneous estimation of both drugs in dry powder for injection dosage form.

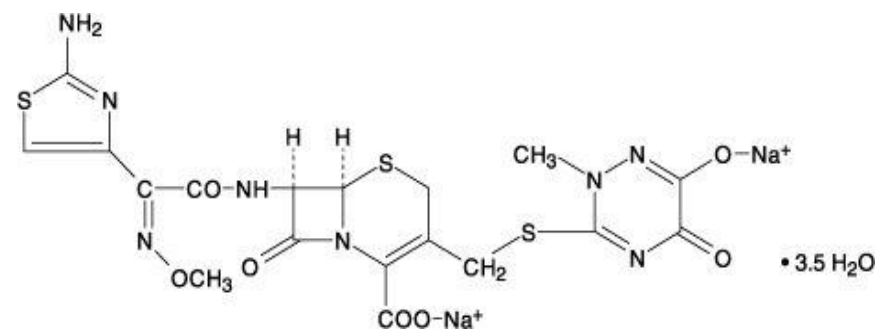

FIG. 1: STRUCTURE OF CEFTRIAXONE SODIUM

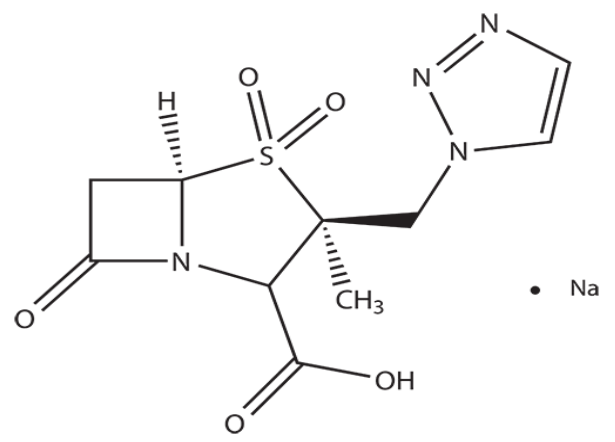

FIG. 2: STRUCTURE OF TAZOBACTAM SODIUM

\section{MATERIALS \& METHODS:}

Apparatus: The chromatography was performed on a Waters (Acquity) RP-UPLC instrument equipped with PDA detector and Em-power 2 software, Acquity UPLC BEH C18 column (100 $\mathrm{mm} \times 2.1 \mathrm{~mm} \mathrm{ID}, 1.7 \mu \mathrm{m})$ was used as stationary phase. Mettler Toledo analytical balance (Germany), an ultrasonic cleaner (Frontline FS 4, Mumbai, India) and Whatmann filter paper No. 41 (Whatman International Ltd., England) were used in the study.

Reagents and materials: Ceftriaxone and Tazobactam bulk powder was obtained from Nirlife, Healthcare division of Nirma Ltd. Ahmedabad, India. The commercial fixed dose combination product was procured from the Nirlife. Acetonitrile (HPLC grade, Finar Reagent,
Ahmedabad, India), Potassium di-hydrogen orthophosphate anhydrous (AR, Finar Reagent, Ahmedabad, India), Disodium hydrogen phosphate anhydrous (AR, Finar Reagent, Ahmedabad, India), Citric acid monohydrate (AR, Finar Reagent, Ahmedabad, India), Tetradecyl ammonium bromide (HPLC Grade, Molychem, Ahmedabad, India), Tetraheptyl ammonium bromide (HPLC grade, Finar Reagent, Ahmedabad, India), Sodium hydroxide (AR, Finar Reagent, Ahmedabad, India), Orthophosphoric acid (AR, Finar Reagent, Ahmedabad, India), used were of HPLC grade was used in the study.

Chromatographic condition: In this work, we used reverse phase Acquity UPLC BEH C18 column $(100 \mathrm{~mm} \times 2.1 \mathrm{~mm} \mathrm{ID}, 1.7 \mu \mathrm{m})$, Waters $)$ as stationary phase and using a mobile phase. In Mobile phase, Solution A containing Potassium Dihydrogen Phosphate buffer ( $\mathrm{pH}$ adjusted to $6.5 \pm 0.2$ with Orthophosphoric acid), Citric acid buffer (pH adjusted to $5.0 \pm 0.2$ with $\mathrm{NaOH}$ solution) and Acetonitrile and Solution B containing Tetradecyl ammonium bromide, Tetraheptyl ammonium bromide and Acetonitrile. Volume of solution A and Solution B taken in the ratio 65:35 $(\mathrm{v} / \mathrm{v})$ for mobile phase, in the flow rate of 0.3 $\mathrm{ml} / \mathrm{min}$.

\section{Preparation of mobile phase:}

- Solution A: Accurately weighed and dissolved about 3.5 gm of Potassium di-hydrogen orthophosphate anhydrous and 14.5 gm of Disodium hydrogen phosphate anhydrous in $1000 \mathrm{ml}$ of water for $\mathrm{pH} 6.5$ Buffer solution. $\mathrm{pH}$ of $6.5 \pm 0.2$ was adjusted by using diluted orthophosphoric acid. Accurately weighed and dissolved about $20.5 \mathrm{gm}$ of Citric acid in $1000 \mathrm{ml}$ of water for $\mathrm{pH} 5.0$ Buffer solution. $\mathrm{pH}$ of $5.0 \pm 0.2$ was adjusted by using $\mathrm{NaOH}$ solution. Water, $\mathrm{pH}$ 6.5 buffer, pH 5.0 buffer and acetonitrile taken in the ratio 600:180:20:200 (v/v) and mix well.

- Solution B: Accurately weighed and dissolved $4.0 \mathrm{gm}$ of Tetradecyl ammonium bromide and $4.0 \mathrm{gm}$ of Tetraheptyl ammonium bromide in $500 \mathrm{ml}$ of acetonitrile sonicated to dissolve and made up to $1000 \mathrm{ml}$ with acetonitrile and mix well. 
- Mobile phase: Volume of solution (A) and Solution (B) taken in the ratio 65:35 (v/v) and mixed well and filter through $0.45 \mu \mathrm{m}$ membrane filter and degas for 10 minutes.

Preparation of standard stock solutions: An accurately weighed Ceftriaxone $(40 \mathrm{mg})$ and Tazobactam $(5 \mathrm{mg})$ were transferred to $100 \mathrm{ml}$ volumetric flask, dissolved in $50 \mathrm{ml}$ with Mobile phase and diluted up to mark with Mobile phase to get $400 \mu \mathrm{g} / \mathrm{ml}$ solution of Ceftriaxone and $50 \mu \mathrm{g} / \mathrm{ml}$ solution of Tazobactam.

Method Validation: The method was validated in compliance with ICH guidelines ${ }^{9}$.

Preparation of calibration curve: Aliquots (of $1,2,3,4,5,6,7 \mathrm{ml})$ of mixed standard working solutions (equivalent to 40,80,120,160,200,240,280 ppm of Ceftriaxone and 5,10,15,20,25,30,35 ppm of Tazobactam) were transferred in a series of 10 $\mathrm{ml}$ volumetric flasks, and the volume was made up to the mark with Mobile phase. Each solution was injected under the operating chromatographic condition as described above and responses were recorded. Calibration curves were constructed by plotting the peak areas versus the concentration, and the regression equations were calculated (Table 1 and Table 2) and (Fig. 3 and Fig. 4). Each response was average of three determinations.

\section{TABLE 1: LINEARITY OF CEFTRIAXONE}

\begin{tabular}{cccc}
\hline $\begin{array}{c}\text { Concentration } \\
(\mathbf{p p m})\end{array}$ & $\begin{array}{c}\text { Average } \\
\text { Area }\end{array}$ & SD & \% RSD \\
\hline 40 & 390859 & 641.9 & 0.164 \\
80 & 782138 & 867.8 & 0.111 \\
120 & 1172548 & 1189.4 & 0.101 \\
160 & 1563607 & 1827.0 & 0.117 \\
200 & 1955229 & 2143.1 & 0.110 \\
240 & 2346153 & 3222.5 & 0.137 \\
280 & 2713442 & 4001.7 & 0.147 \\
\hline
\end{tabular}

TABLE 2: LINEARITY OF TAZOBACTAM

\begin{tabular}{cccc}
\hline $\begin{array}{c}\text { Concentration } \\
(\mathbf{p p m})\end{array}$ & $\begin{array}{c}\text { Average } \\
\text { Area }\end{array}$ & SD & \% RSD \\
\hline 5 & 4242 & 10.3 & 0.242 \\
10 & 8549 & 30.3 & 0.354 \\
15 & 12648 & 45.9 & 0.363 \\
20 & 16932 & 20.3 & 0.120 \\
25 & 21183 & 47.9 & 0.226 \\
30 & 25284 & 30.8 & 0.122 \\
35 & 29070 & 10.0 & 0.034 \\
\hline
\end{tabular}

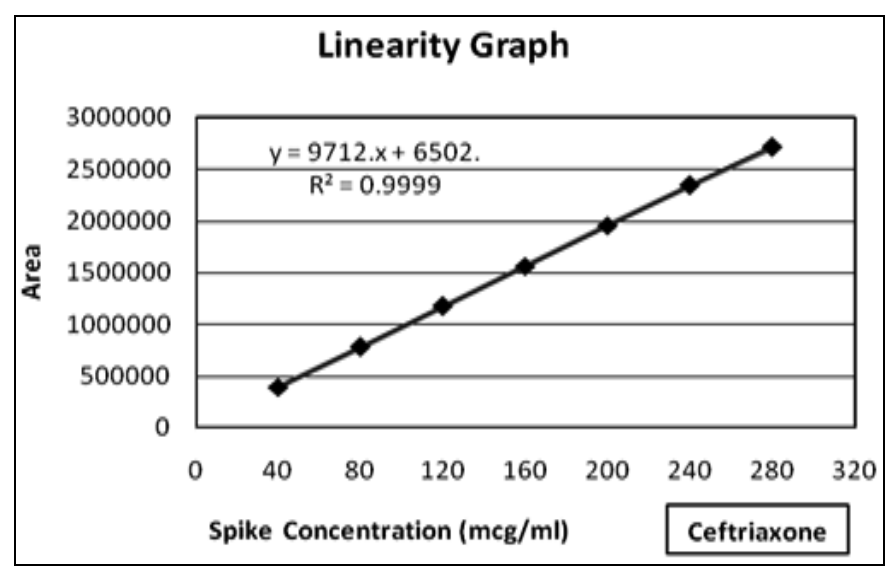

FIG. 3: LINEARITY OF CEFTRIAXONE

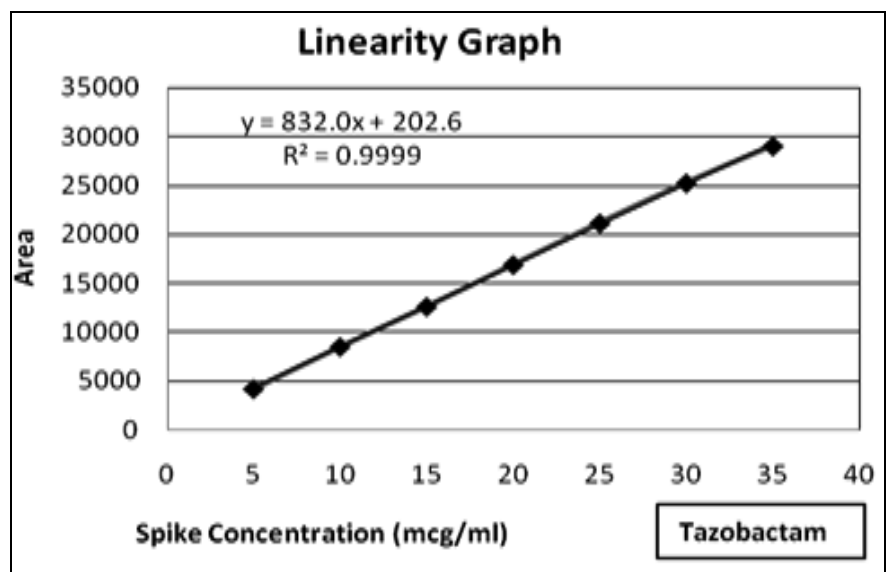

FIG. 4: LINEARITY OF TAZOBACTAM

Accuracy (recovery study): The accuracy of the method was determined by calculating the recoveries of Ceftriaxone and Tazobactam by the standard addition method. Known amounts of standard solutions of Ceftriaxone and Tazobactam were at added at 80, 100 and $120 \%$ level to prequantified sample solutions of Ceftriaxone sodium equivalent to Ceftriaxone $400 \mu \mathrm{g} / \mathrm{ml}$ and Tazobactam $50 \mu \mathrm{g} / \mathrm{ml}$. The amounts of Ceftriaxone and Tazobactam were estimated by applying obtained values to the respective regression line equations (Table 3).

Method precision (Repeatability): The precision of the instrument was checked by repeatedly injecting $(n=6)$ solutions of Ceftriaxone and Tazobactam $(400 \mu \mathrm{g} / \mathrm{ml}$ and $50 \mu \mathrm{g} / \mathrm{ml}$ respectively) without changing the parameters (Table 3).

Intermediate precision (reproducibility): The intraday and inter day precisions of the proposed method was determined by estimating the corresponding responses 3 times on the same day and on 3 different days over a period of one week 
for 3 different concentrations of standard solutions of Ceftriaxone sodium equivalent to Ceftriaxone $(200,400$, and $600 \mu \mathrm{g} / \mathrm{ml})$ and Tazobactam $(25,50$ and $75 \mu \mathrm{g} / \mathrm{ml})$. The results were reported in terms of relative standard deviation (\% RSD) (Table 3).

TABLE 3: SUMMARY OF VALIDATION PARAMETER FOR CEF AND TAZ

\begin{tabular}{ccc}
\hline Parameters & \multicolumn{2}{c}{ RP-UPLC method } \\
\cline { 2 - 3 } Concentration range $(\mathrm{ppm})$ & $40-280$ & Tazobactam \\
Slope & 9712 & $5-35$ \\
Intercept & 6502 & 832 \\
Correlation coefficient & 0.9999 & 202.6 \\
LODa $(\mu \mathrm{g} / \mathrm{ml})$ & 0.005 & 0.9999 \\
LOQb $(\mu \mathrm{g} / \mathrm{ml})$ & 0.017 & 0.125 \\
Repeatability $(\% \mathrm{RSDd}, \mathrm{n}=6)$ & 0.258 & 0.416 \\
& Precision $(\boldsymbol{\%} \mathbf{R S D})$ & 0.210 \\
Inter day $(\mathrm{n}=3)$ & $0.080-0.345$ & $0.045-0.321$ \\
Intraday $(\mathrm{n}=3)$ & $0.055-0.136$ & $0.055-0.090$ \\
Accuracy $(\% \mathrm{RSDd})$ & $0.045-0.075$ & $0.033-0.085$ \\
\hline
\end{tabular}

$\mathrm{a}=$ Limit of detection, $\mathrm{b}=$ Limit of quantification, $\mathrm{n}=$ number of determinations, $\mathrm{d}=$ Relative standard deviation

System suitability: The parameters used in system suitability test were asymmetry of the chromatographic peak, peak resolution and theoretical plates, as \% RSD of peak area for replicate injections (Table 4).

TABLE 4: SYSTEM SUITABILITY TEST PARAMETERS FOR CEF AND TAZ

\begin{tabular}{ccc}
\hline Parameters & CEF \pm \% RSD & TAZ \pm \% RSD \\
\hline Retention Time $(\min )$ & $2.828 \pm 0.112$ & $1.718 \pm 0.074$ \\
Tailing Factor & $1.48 \pm 0.509$ & $1.19 \pm 0.462$ \\
Theoretical Plates & $8681 \pm 0.428$ & $11738 \pm 0.492$ \\
Resolution & \multicolumn{2}{c}{$11.20 \pm 0.087$} \\
\hline
\end{tabular}

Preparation of Marketed sample solution for Assay: For determination of the content of Ceftriaxone and Tazobactam in dry powder for injection; take about $55 \mathrm{mg}$ (Ceftriaxone sodium equivalent to Ceftriaxone $40 \mathrm{mg}$ and Tazobactam sodium equivalent to Tazobactam $5 \mathrm{mg}$ ) of powder and transferred to $100 \mathrm{ml}$ volumetric flask, dissolved in Mobile phase $(50 \mathrm{ml})$ sonicated for 30 min and dilute up to the mark with Mobile phase. The solution was filtered through Whatmann filter paper No. 41 and residue was washed with Mobile phase. The solution was diluted up to the mark with Mobile phase to get final working concentration of Ceftriaxone sodium equivalent to Ceftriaxone (400 $\mu \mathrm{g} / \mathrm{ml}$ ) and Tazobactam sodium equivalent to Tazobactam $(50 \mu \mathrm{g} / \mathrm{ml})$. A sample solution was injected under the operating chromatographic condition as described above and responses were recorded (Fig. 5) and (Table 5). The analysis procedure was repeated three times with dry powder for injection formulation.

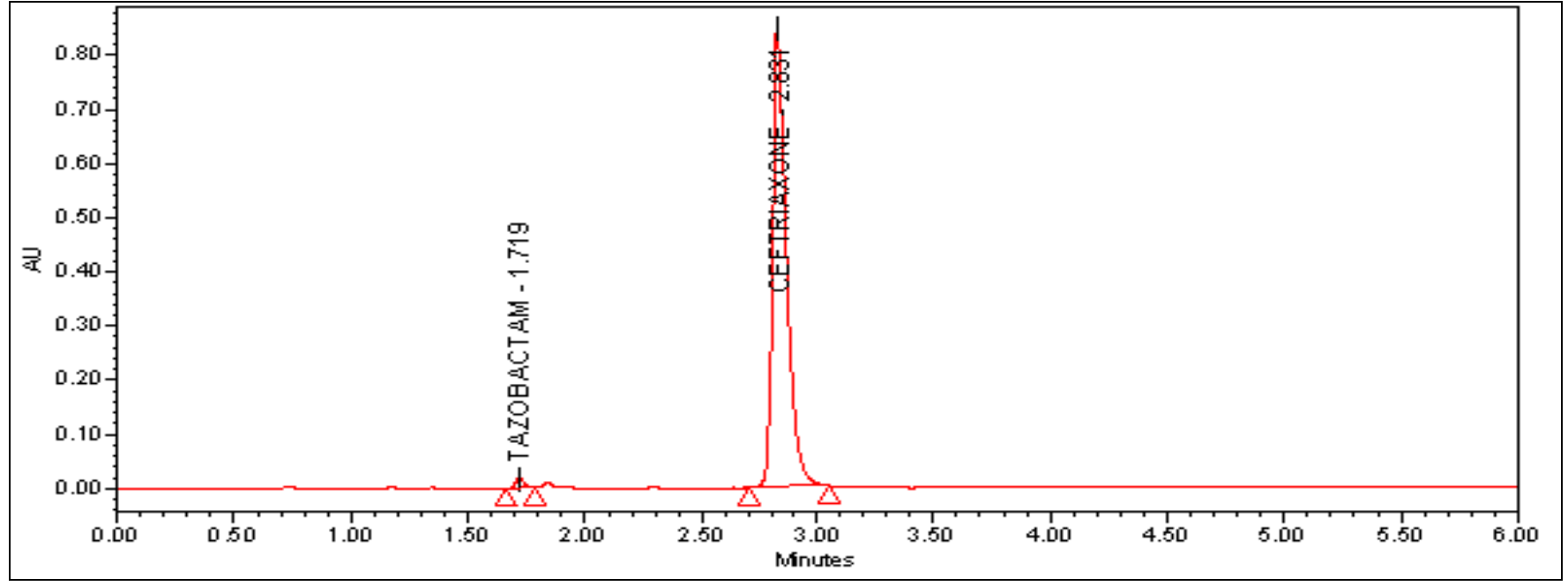

FIG. 5: OPTIMIZED CONDITION CHROMATOGRAM OF ASSAY OF DRUG 
TABLE 5: ANALYSIS OF MARKETED FORMULATION OF CEF AND TAZ

\begin{tabular}{ccccccc}
\hline \multirow{3}{*}{ Injection } & \multicolumn{2}{c}{ Label Claim } & \multicolumn{2}{c}{ Amount Found } & \multicolumn{2}{c}{ \% Label Claim \pm \% RSD $(\mathbf{n}=\mathbf{3})$} \\
\cline { 2 - 5 } & \multicolumn{2}{c}{$\mathbf{1 1 2 5} \mathbf{~ m g} /$ Vial } & & & & \\
\cline { 2 - 6 } & $\mathbf{C E F}$ & TAZ & CEF & TAZ & CEF & TAZ \\
\hline 1 & $1000 \mathrm{MG}$ & $125 \mathrm{MG}$ & 999.6 & 124.9 & $99.96 \pm 0.015$ & $99.92 \pm 0.031$ \\
\hline
\end{tabular}

RESULTS AND DISCUSSION: To optimize the RP-UPLC parameters, several mobile phase compositions were tried. A satisfactory separation and good peak symmetry for Ceftriaxone and Tazobactam were obtained with a mobile phase. In moble phase, Solution A containing Potassium Dihydrogen Phosphate buffer ( $\mathrm{pH}$ adjusted to $6.5 \pm 0.2$ with Orthophosphoric acid), Citric acid buffer (pH adjusted to 5.0 \pm 0.2 with $\mathrm{NaoH}$ solution) and Acetonitrile and Solution B containing Tetradecyl ammonium bromide, Tetraheptyl ammonium bromide and Acetonitrile at a flow rate of $0.3 \mathrm{ml} / \mathrm{min}$ to get better reproducibility and repeatability.

Quantification was achieved with PDA detection at $230 \mathrm{~nm}$ based on peak area. The retention time for Ceftriaxone and Tazobactam were found to be 2.83 and $1.72 \mathrm{~min}$, respectively (Fig. 5). Linear correlation was obtained between peak area versus concentrations of Ceftriaxone and Tazobactam in the concentration ranges of concentration range of $40-280 \mu \mathrm{g} / \mathrm{ml}$ and $5-35 \mu \mathrm{g} / \mathrm{ml}$ are $\mathrm{r}^{2}=0.9999$ and $\mathrm{r}^{2}=0.9999$ and mean accuracies $99.96 \pm 0.015 \%$ and $99.92 \pm 0.031 \%$ for Ceftriaxone and Tazobactam (Table 5), which indicates accuracy of the proposed method.
The \% RSD values for Ceftriaxone and Tazobactam were found to be $<2 \%$, which indicates that the proposed method is repeatable. The low \% RSD values of repeatability of assay $(0.258-0.210 \%)$, inter day $(0.080-0.345 \%$ and $0.045-0.321 \%)$ and intraday $(0.055-0.136 \%$ and 0.055-0.090\%) variations for Ceftriaxone and Tazobactam, respectively, reveal that the proposed method is precise. LOD values for Ceftriaxone and Tazobactam were found to be $0.005 \mu \mathrm{g} / \mathrm{ml}$ and $0.125 \mu \mathrm{g} / \mathrm{ml}$, respectively and LOQ values for Ceftriaxone and Tazobactam were found to be $0.017 \mu \mathrm{g} / \mathrm{ml}$ and $0.416 \mu \mathrm{g} / \mathrm{ml}$, respectively (Table 3). These data show that the proposed method is sensitive for the determination of Ceftriaxone and Tazobactam. The results of system suitability testing are given in (Table 4).

Degradation study of Ceftriaxone and Tazobactam in $0.1 \mathrm{~N} \mathrm{HCl}$ at $70^{\circ} \mathrm{C}$ for 4 hours in reflux condition: Ceftriaxone and Tazobactam peak was observed at retention time $2.831 \mathrm{~min}$ and 1.719 min respectively (Fig. 6). The \% drug degradation observed of Ceftriaxone and Tazobactam was $24.00 \%$ and $11.62 \%$ respectively (Table 6). From this it is observed that Ceftriaxone showed maximum degradation in Acid hydrolysis degradation condition.

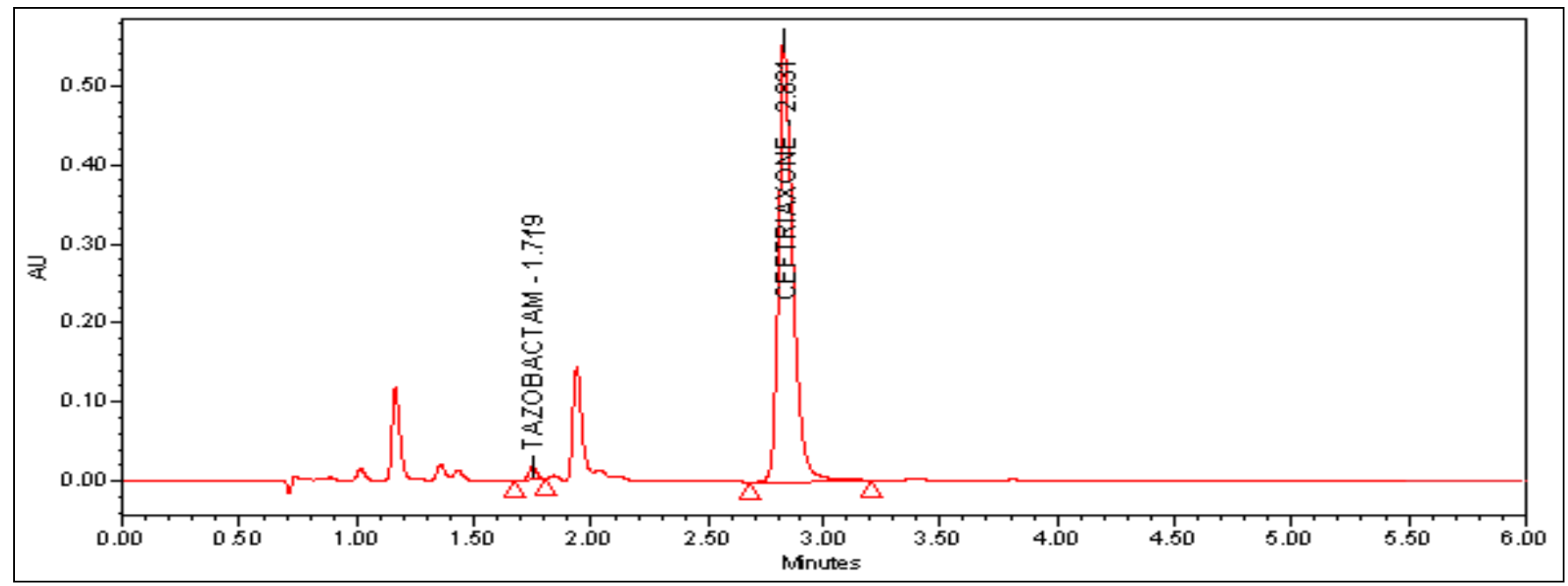

FIG. 6: ACID HYDROLYSIS OF CEFTRIAXONE AND TAZOBACTAM 
Degradation study of Ceftriaxone and Tazobactam in $0.1 \mathrm{~N} \mathrm{NaOH}$ at $70^{\circ} \mathrm{C}$ for 4 hours in reflux condition: Ceftriaxone and Tazobactam peak was observed at retention time $2.739 \mathrm{~min}$ and 1.711 min respectively (Fig. 7). The \% drug degradation observed of Ceftriaxone and Tazobactam was $16.84 \%$ and $27.60 \%$ respectively (Table 6). From this it is observed that Tazobactam showed maximum degradation in base hydrolysis degradation condition.

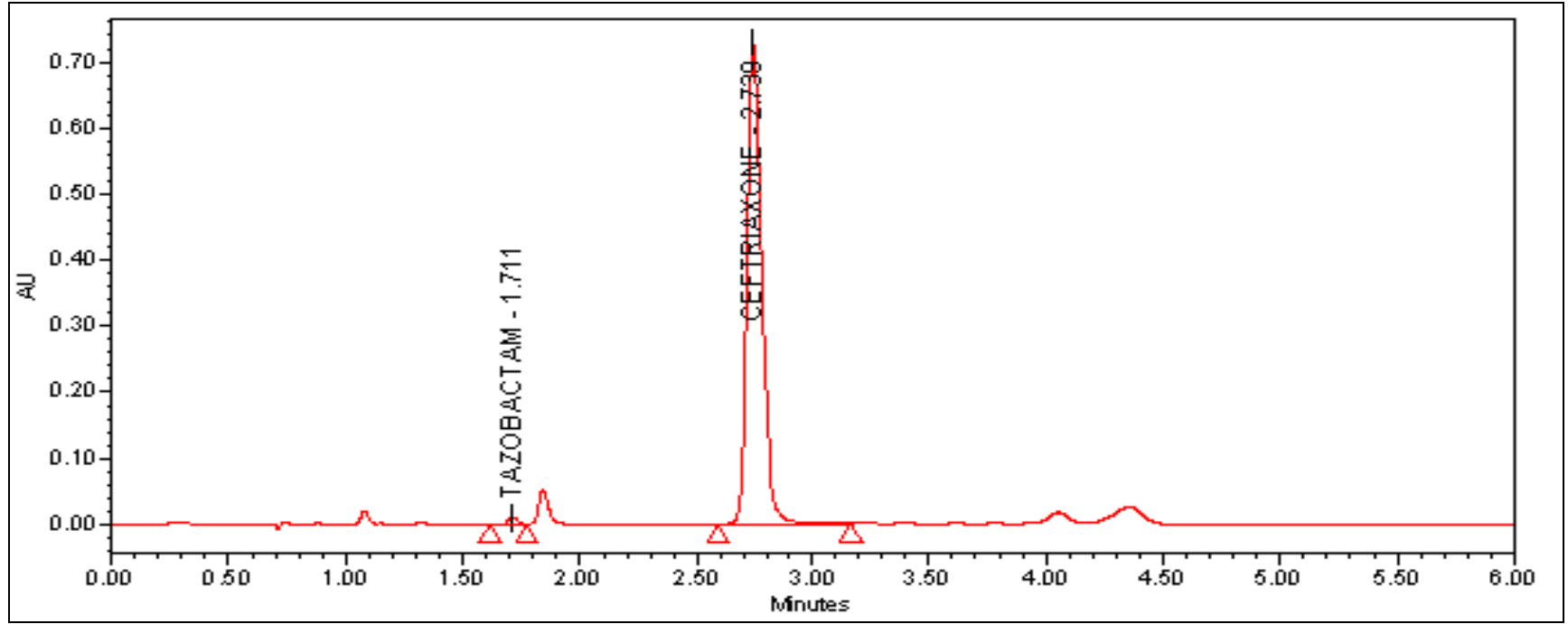

FIG. 7: BASE HYDROLYSIS OF CEFTRIAXONE AND TAZOBACTAM

Oxidation degradation study of Ceftriaxone and Tazobactam in $2 \% \mathrm{H}_{2} \mathrm{O}_{2}$ at $70^{\circ} \mathrm{C}$ for about 1 hour in reflux condition: Sample and drug substances were treated with $2 \%$ solution of hydrogen peroxide and kept in water bath at $70^{\circ} \mathrm{C}$ in reflux condition for about 1 hour. It showed a peak of degradation product. Ceftriaxone and Tazobactam peak was observed at retention time $2.739 \mathrm{~min}$ and $1.711 \mathrm{~min}$ respectively (Fig. 8). The $\%$ degradation observed of Ceftriaxone and Tazobactam was $13.40 \%$ and $7.78 \%$ respectively (Table 6).

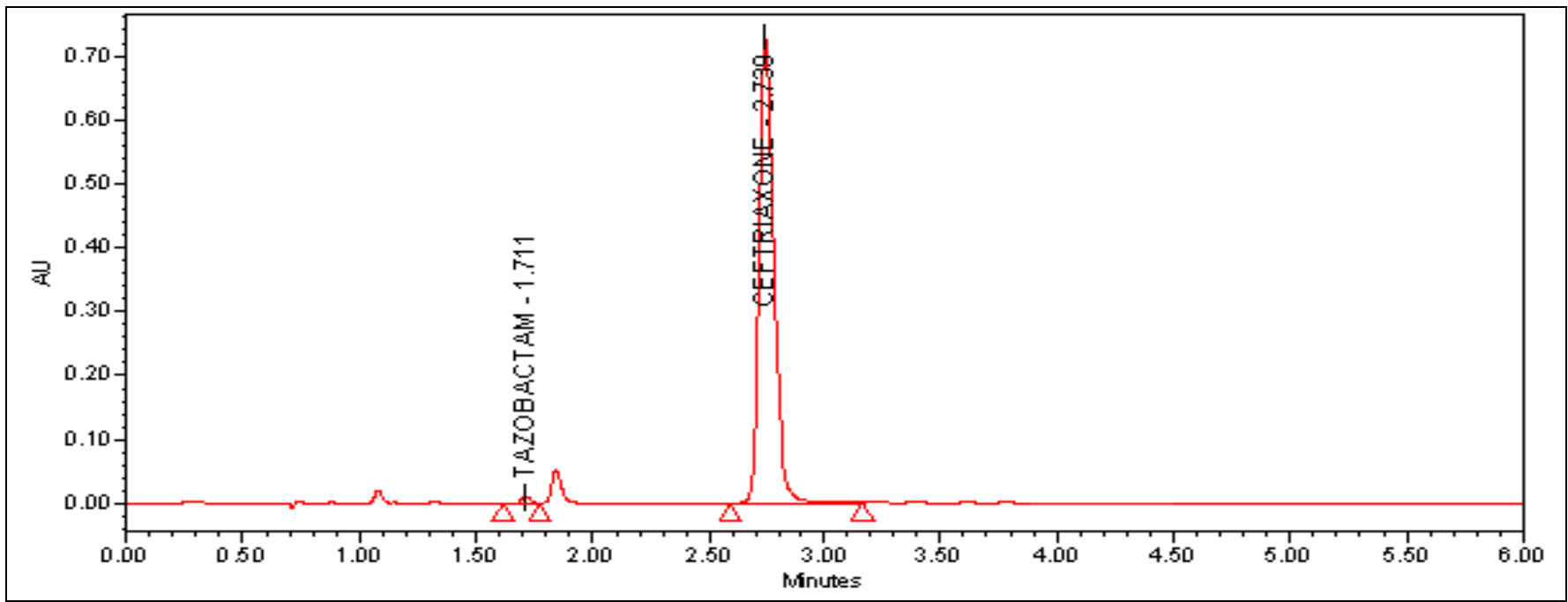

FIG. 8: OXIDATION OF CEFTRIAXONE AND TAZOBACTAM

Thermal Degradation study of Ceftriaxone and Tazobactam at $60^{\circ} \mathrm{C}$ for about 24 hrs: Thermal degradation of Ceftriaxone and Tazobactam at $60^{\circ} \mathrm{C}$ for about $24 \mathrm{hrs}$ in hot air oven was carried out.
There was no degradation peak found in thermal degradation chromatogram because there was lower degradation found in thermal degradation study. \%Degradation of Ceftriaxone and Tazobactam was found to be $0.71 \%$ and $0.53 \%$ respectively (Fig. 9 and Table 6). 


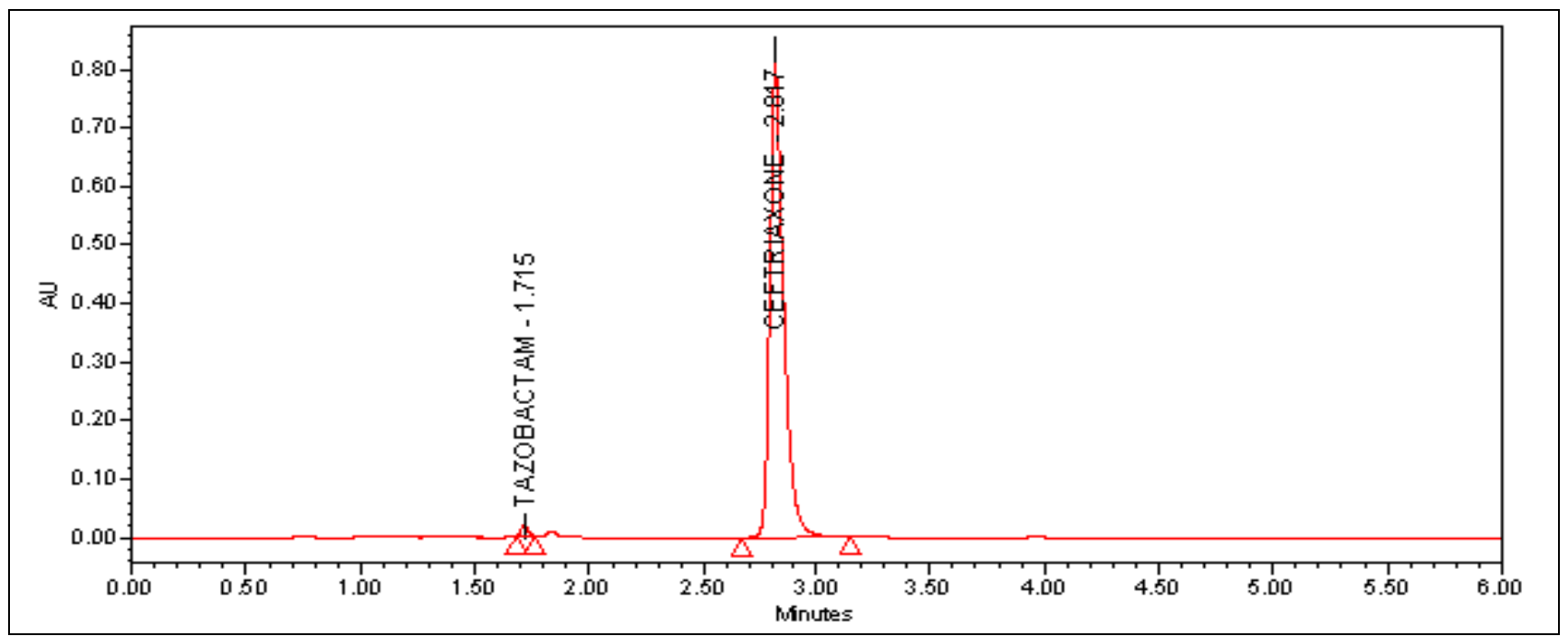

FIG. 9: THERMAL DEGRADATION OF CEFTRIAXONE AND TAZOBACTAM

Photolytic Degradation study of Ceftriaxone and Tazobactam: Sample and drug substances were exposed to energy of 1.2 million lux hrs fluorescent light and $200 \mathrm{w} / \mathrm{m}^{2}$ of UV for about 7 days. \% degradation of Ceftriaxone and Tazobactam was found to be $6.47 \%$ and $3.35 \%$ respectively (Fig. 10 and Table 6).

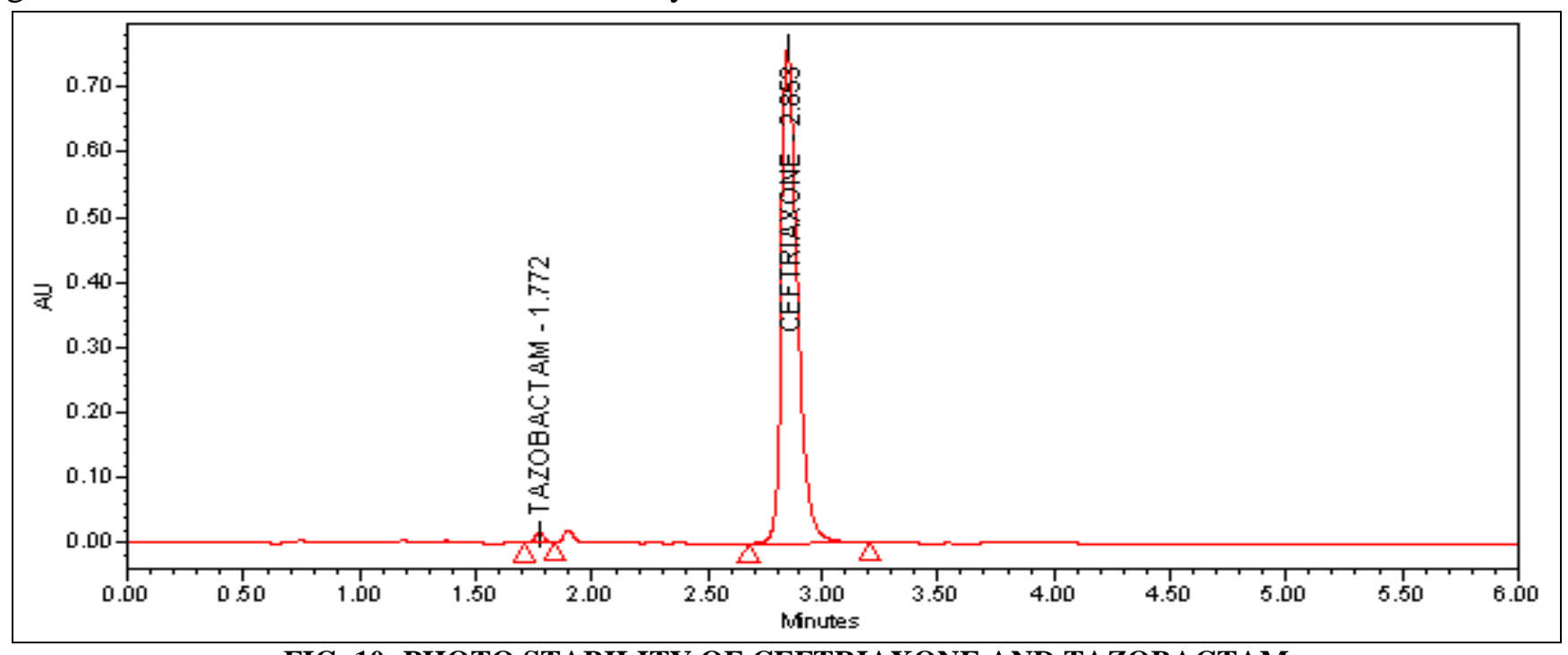

FIG. 10: PHOTO STABILITY OF CEFTRIAXONE AND TAZOBACTAM

TABLE 6: \%DEGRADATION OF CEFTRIAXONE AND TAZOBACTAM IN DIFFERENT CONDITIONS

\begin{tabular}{|c|c|c|c|c|c|c|c|c|}
\hline \multirow[t]{2}{*}{ Degradation condition } & \multicolumn{2}{|c|}{ Area } & \multicolumn{2}{|c|}{$\begin{array}{l}\text { Concentration } \\
\text { In } \mathrm{mcg} / \mathrm{ml}\end{array}$} & \multicolumn{2}{|c|}{$\%$ Potency } & \multicolumn{2}{|c|}{ \% Degradation } \\
\hline & CEF & TAZ & CEF & TAZ & CEF & TAZ & CEF & TAZ \\
\hline \multirow{2}{*}{$\begin{array}{l}\text { Acidic/ } 0.1 \mathrm{~N} \mathrm{HCl} / 70^{\circ} \mathrm{C} / \text { Reflux } / 4 \mathrm{hr} / \\
\text { Solution }\end{array}$} & 3946757 & 42940 & 399.84 & 49.96 & 99.96 & 99.92 & \multirow{2}{*}{24.00} & \multirow{2}{*}{11.62} \\
\hline & 2945456 & 35918 & 303.84 & 44.15 & 75.96 & 88.30 & & \\
\hline \multirow{2}{*}{$\begin{array}{c}\text { Alkaline } / 0.1 \mathrm{~N} \mathrm{NaOH} / 70^{\circ} \mathrm{C} / \text { Reflux } / 4 \\
\mathrm{hr} / \text { Solution }\end{array}$} & 3946757 & 42940 & 399.84 & 49.96 & 99.96 & 99.92 & \multirow{2}{*}{16.84} & \multirow{2}{*}{27.60} \\
\hline & 3223288 & 29412 & 332.48 & 36.16 & 83.12 & 72.32 & & \\
\hline \multirow{2}{*}{$\begin{array}{c}\text { Oxidative } / 2 \% \mathrm{H}_{2} \mathrm{O}_{2} / 70^{\circ} \mathrm{C} / \text { Reflux/ } 1 \mathrm{hr} / \\
\text { Solution }\end{array}$} & 3946757 & 42940 & 399.84 & 49.96 & 99.96 & 99.92 & \multirow{2}{*}{13.40} & \multirow{2}{*}{7.78} \\
\hline & 3356452 & 37473 & 346.24 & 46.07 & 86.56 & 92.14 & & \\
\hline \multirow{2}{*}{ Thermal $/ 60^{\circ} \mathrm{C} / 24 \mathrm{hr} /$ Solid } & 3978274 & 43271 & 399.92 & 49.94 & 99.98 & 99.88 & \multirow{2}{*}{0.71} & \multirow{2}{*}{0.53} \\
\hline & 3880191 & 40718 & 397.08 & 49.67 & 99.27 & 99.35 & & \\
\hline \multirow{2}{*}{$\begin{array}{l}\text { Photo/1.2 million lux hrs fluorescent } \\
\text { light } / 200 \mathrm{w} / \mathrm{m}^{2} \text { of UV/7 days }\end{array}$} & 3978274 & 43271 & 399.92 & 49.94 & 99.98 & 99.88 & \multirow{2}{*}{6.47} & \multirow{2}{*}{3.35} \\
\hline & 3654856 & 39564 & 374.04 & 48.26 & 93.51 & 96.53 & & \\
\hline
\end{tabular}


CONCLUSION: Stability indicating RP-UPLC methods for estimation of Ceftriaxone and Tazobactam in their combine dosage form was established and validated as per the ICH guidelines. The forced degradation study and peak purity data confirmed that there was no merging between peaks of active ingredients and any other degradation products as well as other additives. Hence the specificity of the proposed method was established.

The linearity of developed method was achieved in the range of $40-280 \mu \mathrm{g} / \mathrm{ml}$ for Ceftriaxone $\left(\mathrm{r}^{2}=0.9999\right)$ and $5-35 \mu \mathrm{g} / \mathrm{ml}$ for Tazobactam $\left(r^{2}=0.9999\right)$. The percentage recovery of drug was achieved in the range of 98-101 \% which was within the acceptance criteria. The percentage RSD was NMT $2 \%$ which proved the precision of the developed method. Different degradation products were found for drug product in acidic, alkaline, oxidative, thermal and photolytic force degradation.

Peak of Degraded products were not interfering with the main drug peak of Ceftriaxone and Tazobactam. Thus, these degradation products have not been identified.

The developed method is simple, sensitive, rapid, linear, precise, rugged, accurate, specific, and robust. Hence it can be used for the routine analysis of Ceftriaxone and Tazobactam in their bulk and combine dosage form in quality control laboratory and stability studies.
ACKNOWLEDGEMENT: The authors are thankful to Nirlife HealthCare, Ahmedabad, India for providing a Sample and facilities for research.

\section{REFERENCES:}

1. Indian Pharmacopeia, Government of India, Ministry of Health \& Family welfare, The Indian pharmacopeia commission, Ghaziabad, Vol. II, 2010: 1024-1026.

2. British Pharmacopeia, The Department of Health, British Pharmacopeia Commission, London, Vol. III, 2013: 26352636.

3. The United State Pharmacopeia, United States Pharmacopeial Convention, Rockville, Vol. II, 2013: 2891-2892.

4. Sharma S and Sharma MC: Simultaneous Estimation and Validation of Ceftriaxone Sodium and Tazobactum Sodium from Pharmaceutical Dosage Using Indigo carmine, Methyl orange dye. World Journal of Chemistry 2011; 6(1): 53-58.

5. Gandhimathi M, Saravanakumar $M$ and Ravi TK: Validated ion pair HPLC Method for simultaneous estimation of Ceftriaxone Sodium and Tazobactam Sodium in Dosage form. International Journal of Pharma and Bio Sciences 2010; 1(4): 17-22.

6. Sunder N and Bhanu R: Simultaneous estimation of ceftriaxone and tazobactam using stability indicating hplc method. The Indian pharmacist 2007; 6(63): 74-81.

7. Nanda Rabindra K. and Shelke Ashwini V: Development and Validation of RP-HPLC Method for the Simultaneous Estimation of Ceftazidime Sodium and Tazobactam Sodium in Marketed Formulation. International Journal of PharmTech Research 2013; 5(3): 983-990.

8. Shrestha B, Bhuyan N. and Sinha B: Development and Validation of A Stability Indicating HPLC Method for Estimation of Ceftriaxone and Sulbactam in Sterile Powder or Injection. International Journal of PharmTech Research 2012; 4(4):1660-1666.

9. ICH, Q2 (R1), Harmonised tripartite guideline, Validation of analytical procedures: text and methodology International Conference on Harmonization ICH, Geneva, 2005 .

\section{How to cite this article:}

Panchal VJ, Desai HT and Dave AG: Development and validation of stability indicating method for simultaneous estimation of ceftriaxone and tazobactam injection using RP-UPLC method. Int J Pharm Sci Res 2014; 5(6): 2398-05.doi: 10.13040/IJPSR.0975-8232.5(6).2398-05

All () 2013 are reserved by International Journal of Pharmaceutical Sciences and Research. This Journal licensed under a Creative Commons Attribution-NonCommercial-ShareAlike 3.0 Unported License.

This article can be downloaded to ANDROID OS based mobile. Scan QR Code using Code/Bar Scanner from your mobile. (Scanners are available on Google Playstore) 